\title{
Adsorption characteristics of a ready-made mixture of linseed and dried fruit
}

\author{
Albena Durakova ${ }^{1, *}$, Adelina Vasileva $^{2}$, and Kornelia Choroleeva ${ }^{3}$ \\ ${ }^{1}$ Department of Process Engineering, Technical Faculty, University of Food Technologies, Plovdiv, Bulgaria \\ ${ }^{2}$ Department of Mechanical and Instrument Engineering, Faculty of Mechanical Engineering, Branch Plovdiv of Technical University, \\ Sofia, Bulgaria \\ ${ }^{3}$ Language Training Center, University of Food Technologies, Plovdiv, Bulgaria
}

\begin{abstract}
Sorption characteristics are an integral part of scientific research on new products since they provide data on the means of processing, transportation, and storage of food products. The present study focuses on the adsorption characteristics of a ready-made mixture of golden linseed - $46 \%$; brown linseed $25 \%$; granulated plums $-9 \%$ and granulated dates $-8 \%$ which are organic farming ingredients. The experiment was conducted at temperatures of $10^{\circ} \mathrm{C}, 25^{\circ} \mathrm{C}$ and $40^{\circ} \mathrm{C}$ and water activities in the $11.2 \%-86.8 \%$ range. The results demonstrate that at constant water activities the increase in temperature is coupled by a decrease in equilibrium moisture content. The sorption isotherms obtained belong to Type III, typical of food products, according to the classification of Brunauer et al. For the description of adsorption isotherms, we recommend Oswin's modified three-parameter model. Via the linearization of Brunauer-Emmett-Teller's model, we calculated the values of the monolayer moisture content (MMC) of the mixture for the three temperatures: $10^{\circ} \mathrm{C}-4.85 \%$ d.m.; $25^{\circ} \mathrm{C}-3.92 \%$ d.m. and $40^{\circ} \mathrm{C}-3.34 \%$ d.m. with control points for water activity of $\mathrm{a}_{\mathrm{w}}<0.5$.
\end{abstract}

\section{Introduction}

The improvement of daily eating habits and the discovery of new sources of synthesized active ingredients are among the major tasks of scientists and manufacturers in the sphere of food and flavor industry. As a result of the latter's cooperation, the usage of ready-made functional mixes is becoming increasingly common.

Plenty of studies prove that food quality - texture, taste, aroma, consumer safety and storage - is directly linked to food moisture [1-2]. The research on sorption characteristics allows for the analysis of the regimes and means of processing, storage, and packaging of foodstuff. The interdependence between equilibrium moisture content (EMC) and water activity $\left(\mathrm{a}_{\mathrm{w}}\right)$ is manifested by the sorption isotherm which is experimentally plotted with reference to specific temperatures. Isotherms can testify to the character and quantity of the various types of bound water. The calculation of monolayer moisture content (MMC) values is of great significance as regards the microbiological stability of food products [3-5].

The world has recognized the necessity for the development of ready mixes rich in biologically active ingredients with a beneficial effect on the immune system preventing against many diseases, including Type 2 diabetes. Diabetes is a pathological process characterized by increased blood sugar levels. Its frequency is progressively increasing. Many statistical data and prerequisites for the disease have been discussed in view of the above-mentioned tendency but a crucial factor is the lack of balance in the diet and the absence of motor activity. Diabetics face the need to follow a special diet, which may lead to a deficiency in certain nutrients in the organism [6-7].

Linseed is among the plants which are widely and successfully used in herbal medicine. Linseed decreases blood sugar and contains plenty of vitamins and trace elements. Its incorporation in diets replenishes the reserves of nutrients which diabetics lack. In the case of diabetes, linseed helps in the stabilization of the amount of glucose, of A, E, B, C, K, and $\mathrm{H}$ vitamins in the human body. It affects beneficially the treatment as well as the entire organism [8-9].

The blue plum is also an extraordinary fruit. It can be consumed raw or incorporated in confectionery, salads, and meat-containing dishes. One of the basic advantages of blue plums is that they are among the ingredients recommended for Type 2 diabetes diets. Blue plums are also high in the vitamins and trace elements needed by the human organism. They can be of great importance to both healthy people and Type 2 diabetics [10-11].

There are many studies determining the glycemic index (low GI = Low-glycemic-index/load) of dates and their effect on diabetes patients. Dates contain $80 \%$ sugar (by weight), which in quantitative terms is a considerably high value, but nevertheless dates do not affect blood sugar levels negatively. In order to prove the latter, Israeli scientists have conducted a small-scale experiment in

\footnotetext{
* Corresponding author: $\underline{\text { aldurakova } @ \text {,abv.bg }}$
} 
which a group of diabetics consume dates in unlimited amounts in the course of a month. At the end of the experiment, the weight and blood sugar levels of all participants have remained the same. Moreover, the triglyceride blood levels have decreased significantly. Another research, conducted in 2011 and published by Nutrition Journal, has focused on the determination of the glycemic index of five subspecies of the date plant. It has shown that glucose levels do not increase and that the moderate consumption of dates as part of a balanced healthy diet is even useful for diabetics [12-13].

Our extensive literature review has not discovered data on the adsorption capacity of mixes containing the four above-mentioned components - golden linseed, brown linseed, granulated blue plums, and granulated dates - which has motivated us to carry out the present study. The analysis is of crucial importance to the achievement of the objectives of the current Scientific Fund project based at the UFT - Plovdiv, namely the preparation of raw bars to be included in the diet of Type 2 diabetics.

\section{Materials and methods}

\subsection{Raw Materials}

C Bio linseed, granulated blue plums and dates purchased in Bulgaria by "Internet café-BG" Ltd and packed by "Zoya bg Organic Shop"

\subsection{Methods}

The present study was based on the static gravimetric method as recommended for food products by the Project COST 90 and modernized by Bell and Labuza, 2000 [14$15]$.

We analyzed the adsorption characteristics of a mixture containing linseed and granulated blue plums and dates for the temperatures of $10^{\circ} \mathrm{C}, 25^{\circ} \mathrm{C}$ and $40^{\circ} \mathrm{C}$ at eight different relative air humidities, achieved by using saturated solutions of salts maintaining constant water activity above its surface $-\mathrm{LiCl}, \mathrm{CH}_{3} \mathrm{COOK}, \mathrm{MgCl}_{2}$, $\mathrm{K}_{2} \mathrm{CO}_{3}, \mathrm{Mg}\left(\mathrm{NO}_{3}\right)_{2}, \mathrm{NaBr}, \mathrm{NaCl}, \mathrm{KCl}$. The samples were pre-dehydrated in a desiccator above diphosphorus pentoxide $\left(\mathrm{P}_{2} \mathrm{O}_{5}\right)$ for 10 days. In order to conduct the analysis, after dehydration, $1.000 \mathrm{~g}$ of the sample was placed in hygrostats. The hygrostats were then positioned in thermostats for a 20-day period at constant temperatures. The hygrostats maintained constant water activity in the $0.112-0.868$ range via saturated salt solutions [16].

Equilibrium moisture content (EMC), \% dry mass was determined via a standard drying method: for $24 \mathrm{~h}$ at $105^{\circ} \mathrm{C}$.

In order to describe sorption isotherms, we applied the modified three-parameter models of Oswin, Chung-Pfost, Halsey and Henderson.
Modified Chung-Pfost

$$
\mathrm{a}_{\mathrm{w}}=\exp \left[\frac{-\mathrm{A}}{\mathrm{t}+\mathrm{B}} \exp (-\mathrm{CM})\right]
$$

Modified Halsey

$$
\mathrm{a}_{\mathrm{w}}=\exp \left[\frac{-\exp (\mathrm{A}+\mathrm{Bt})}{\mathrm{M}^{\mathrm{C}}}\right]
$$

Modified Oswin

$$
M=(A+B t)\left(\frac{a_{w}}{1-a_{w}}\right)^{C}
$$

Modified Henderson

$$
1-\mathrm{a}_{\mathrm{w}}=\exp \left[-\mathrm{A}(\mathrm{t}+\mathrm{B}) \mathrm{M}^{\mathrm{C}}\right]
$$

The determination of $\mathrm{A}, \mathrm{B}$ and $\mathrm{C}$ coefficients resorted to the non-linear regression program "Statistica" following the least squares method ("Nonlinear Estimation" procedure) [16].

Mean relative error, standard deviation and distribution of residuals were the criteria used to evaluate and compare the models.

Mean relative error

$$
\mathrm{P}=\frac{100}{\mathrm{~N}} \sum\left|\frac{\mathrm{M}_{\mathrm{i}}-\widehat{\mathrm{M}}_{\mathrm{i}}}{\mathrm{M}_{\mathrm{i}}}\right|
$$

Standard deviation

$$
\mathrm{SEM}=\sqrt{\frac{\sum\left(\mathrm{M}_{\mathrm{i}}-\widehat{\mathrm{M}}_{\mathrm{i}}\right)^{2}}{\mathrm{df}}}
$$

Residual

$$
\mathrm{e}_{\mathrm{i}}=\mathrm{M}_{\mathrm{i}}-\widehat{\mathrm{M}}_{\mathrm{i}}
$$

where: $M_{i}$ and $\widehat{M}_{i}$ denote the experimental equilibrium moisture and the model-predicted equilibrium moisture, respectively; $\mathrm{N}$ - number of tests; $d f$-degrees of freedom (number of tests minus number of coefficients).

In order to calculate the MMC, we used the linearly transformed Brunauer-Emmett-Teller (BET) model [17]:

$$
\frac{\mathrm{a}_{\mathrm{w}}}{\left(1-\mathrm{a}_{\mathrm{w}}\right) \mathrm{M}}=\mathrm{P}+\mathrm{Q \textrm {a } _ { \mathrm { w } }}
$$

where $P$ and $Q$ are coefficients:

$$
\mathrm{P}=\frac{1}{\mathrm{M}_{\mathrm{e}} \mathrm{C}} \quad \text { and } \quad \mathrm{Q}=\frac{\mathrm{C}-1}{\mathrm{M}_{\mathrm{e}} \mathrm{C}}
$$

All tests were conducted in triplicate runs.

\section{Results and discussion}

Table 1 gives information provided by the manufacturer, on the nutritional value of $100 \mathrm{~g}$ analyzed product: a ready mix of golden linseed $46 \%$; brown linseed $25 \%$; granulated blue plums $9 \%$, and granulated dates $8 \%$. 
Table 1. Nutritional value per $100 \mathrm{~g}$ product.

\begin{tabular}{|l|c|}
\hline Energy & $\mathbf{1 9 8 8 ~} \mathbf{~ J J} / \mathbf{4 8 0}$ kcal \\
\hline Omega-3 Fatty Acids & $12 \mathrm{~g}$ \\
\hline Protein & $19 \mathrm{~g}$ \\
\hline Carbohydrate & $19 \mathrm{~g}$ \\
- of which sugars & $7.8 \mathrm{~g}$ \\
\hline Fat & $30 \mathrm{~g}$ \\
- of which saturated & $2.8 \mathrm{~g}$ \\
- of which monounsaturated & $4.1 \mathrm{~g}$ \\
\hline Dietary Fiber & $29 \mathrm{~g}$ \\
\hline Salt & $<0.01 \mathrm{~g}$ \\
\hline
\end{tabular}

The table shows the big amount of omega- 3 fatty acids and dietary fiber, two components with an extremely beneficial effect on Type 2 diabetics.

The equilibrium moisture content values for adsorption during the experiment can be seen in Table 2 .

Table 2. Equilibrium moisture content of the ready mix during the experiment, $\%$ d.b.

\begin{tabular}{|l|c|c|c|c|c|c|}
\hline & $\mathbf{1 0}^{\circ} \mathbf{C}$ & & $\mathbf{2 5}^{\circ} \mathbf{C}$ & & $\mathbf{4 0}^{\circ} \mathbf{C}$ & \\
\hline Sel & $\mathbf{E M C}^{*}$ & $\mathbf{S D}^{* *}$ & $\mathbf{E M C}^{*}$ & $\mathbf{S D}^{\text {*** }}$ & $\mathbf{E M C}^{*}$ & $\mathbf{S D}^{\text {*** }}$ \\
\hline $\mathbf{L i C l}$ & 4.45 & 0.08 & 3.97 & 0.12 & 1.99 & 0.15 \\
\hline $\mathbf{C H}_{\mathbf{3}} \mathbf{C O O K}$ & 4.52 & 0.09 & 4.46 & 0.11 & 3.58 & 0.07 \\
\hline $\mathbf{M g C l}_{\mathbf{2}}$ & 5.83 & 0.12 & 4.99 & 0.15 & 4.11 & 0.14 \\
\hline $\mathbf{K}_{\mathbf{2}} \mathbf{C O}_{\mathbf{3}}$ & 8.28 & 0.13 & 7.21 & 0.21 & 6.50 & 0.10 \\
\hline $\mathbf{M g N O} \mathbf{3}_{3}$ & 11.50 & 0.18 & 8.73 & 0.19 & 7.12 & 0.21 \\
\hline $\mathbf{N a B r}$ & 14.73 & 0.14 & 9.77 & 0.12 & 7.62 & 0.15 \\
\hline $\mathbf{N a C l}$ & 15.65 & 0.17 & 14.42 & 0.18 & 12.10 & 0.12 \\
\hline $\mathbf{K C l}$ & 29.43 & 0.16 & 20.13 & 0.16 & 18.42 & 0.13 \\
\hline
\end{tabular}

*Mean of three runs

${ }^{* *}$ Mean deviation of three runs

The results prove an interdependence observed throughout the years: the increase in temperature leads to the decrease in equilibrium moisture values in percentages. The greatest decrease is evident at a water activity of $0.868-11.01 \%$ d.m. i.e., from 29.43 at $10^{\circ} \mathrm{C}$ to 18.42 at $40^{\circ} \mathrm{C}$. As regards the other water activity values, the percentage is recognizably lower.

Fig. 1 shows the adsorption isotherms obtained during the experiment.

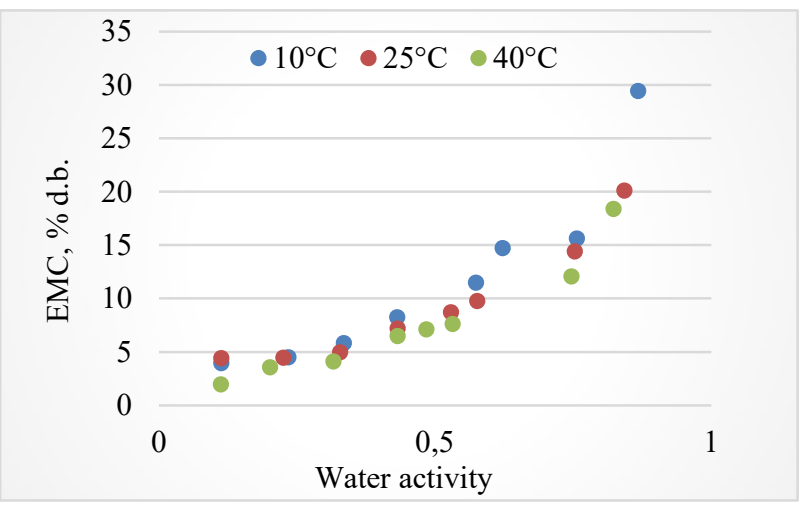

Fig. 1. Adsorption isotherms.

According to the classification of Brunauer et al. for food products, the adsorption isotherms obtained belong to Type III [18].
With the help of statistical processing, we obtained the coefficients of the modified three-parameter models used, as well as the evaluation and suitability criteria presented in Table 3

Table 3. Coefficients of the modified three-parameter models.

\begin{tabular}{|c|c|c|c|c|}
\hline $\begin{array}{c}\text { Models } \\
\text { coefficients }\end{array}$ & Oswin & Halsey & Henderson & $\begin{array}{c}\text { Chung- } \\
\text { Pfost }\end{array}$ \\
\hline A & 10.432 & 2.591 & 0.0007 & 243.76 \\
\hline B & -0.085 & -0.013 & 43.858 & 0.157 \\
\hline C & 0.564 & 1.122 & 1.273 & 62.544 \\
\hline P & $\mathbf{1 0 . 0 5}$ & 11.95 & 13.32 & 19.63 \\
\hline SEM & $\mathbf{1 . 1 1}$ & 1.64 & 1.81 & 2.61 \\
\hline Residuals & Arbitrary & $\begin{array}{c}\text { Non- } \\
\text { arbitrary }\end{array}$ & $\begin{array}{c}\text { Non- } \\
\text { arbitrary }\end{array}$ & $\begin{array}{c}\text { Non- } \\
\text { arbitrary }\end{array}$ \\
\hline
\end{tabular}

Analysing coefficient values, we established that the Oswin model accounts for the lowest values of the widely used criteria of model evaluation and suitability, mean relative error $(\mathrm{P}, \%)$, standard deviation (SEM, \%) and arbitrary distribution of residuals. On the basis of the results, we recommend modified three-parameter Oswin as the most adequate model to describe the adsorption isotherms of the product under study.

Linearizing (Fig. 2) the Brunauer-Emmett-Teller (BET) model, we calculated the monolayer moisture content (MMC) values of the ready-made mixture at a water activity of $\mathrm{a}_{\mathrm{w}}<0.5$. The values obtained for the three temperatures are as follows: $10^{\circ} \mathrm{C}-4.85 \%$ d.m.; $25^{\circ} \mathrm{C}-3.92 \%$ d.m. and $40^{\circ} \mathrm{C}-3.34 \%$ d.m. The results demonstrate that the increase in temperature is accompanied by a decrease in MMC values. In percentages, the decrease in MMC falling within the $10^{\circ} \mathrm{C}-40^{\circ} \mathrm{C}$ range amounts to $1.51 \%$ d.m.

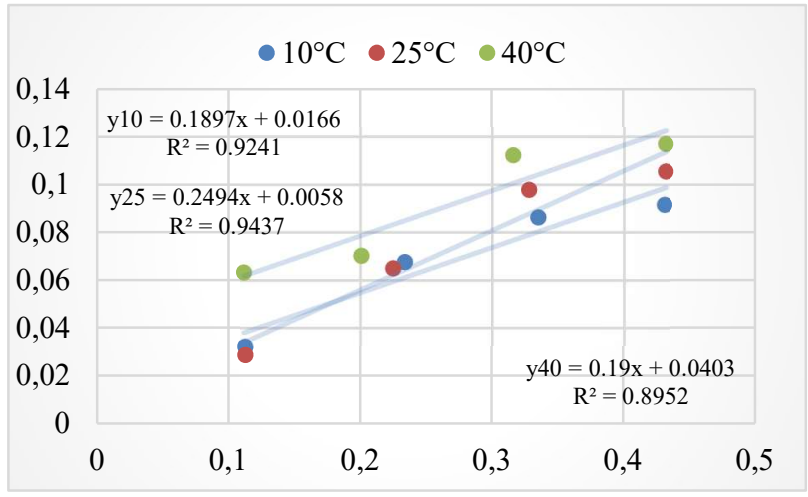

Fig. 2. Linearization of the BET model for adsorption.

\section{Conclusions}

On the basis of the analysis, we obtained data on the equilibrium moisture content values of a ready-made mixture of linseed and granulated blue plums and dates for the three temperatures of $10^{\circ} \mathrm{C}, 25^{\circ} \mathrm{C}$ and $40^{\circ} \mathrm{C}$ and eight water activities within the $11.2-86.8 \%$ range.

The increase in temperature affects equilibrium moisture values. At constant water activity, the increase in temperature is accompanied by a decrease in equilibrium moisture content during the whole time period of the research. 
According to the classification of Brunauer et al. for food products, the adsorption isotherms obtained belong to Type III.

In view of the description of the adsorption isotherms of the ready-made mixture, we recommend the modified three-parameter Oswin model.

We calculated the MMC values for a water activity of $\mathrm{a}_{\mathrm{w}}<0.5$ using the linearized Brunauer-Emmett-Teller model, as follows: $10^{\circ} \mathrm{C}-4.85 \%$ d.m.; $25^{\circ} \mathrm{C}-3.92 \%$ d.m. and $40^{\circ} \mathrm{C}-3.34 \%$ d.m. The results show that temperature affects MMC values since its increase is coupled by their decrease. In percentages, the decrease in $\mathrm{MMC}$ falling within the $10^{\circ} \mathrm{C}-40^{\circ} \mathrm{C}$ range amounts to $1.51 \%$ d.m.

Acknowledgements: This study was part of the Scientific Research Fund "FS N11/20-H", project director: Assoc. Prof. $\mathrm{PhD}$ Albena Georgieva Durakova, University of Food Technologies - Plovdiv, Bulgaria.

\section{References}

1. G. V. Barbosa-Cánovas, A. J. Fontana Jr, S. Schmidt, T. P. Labuza, Water activity in foods: fundamentals and applications (John Wiley \& Sons, Hoboken, NJ, 2020)

2. P. Pittia, P. Antonello, Regulating safety of traditional and ethnic foods) (Academic Press, Elsevier, Cambridge, MA, 2016)

3. K. Muzaffar, P. Kumar, Powder Technol. 291, 322327 (2016)

4. M. Lutovska, V. Mitrevski, T. Geramitcioski, V. Mijakovski, I. Andreevski, J. Proc. Energy Agric. 20, 69-72 (2016)

5. O. Bensebia, K. Allia, J. Appl. Res. Med. Aromat. Plants. 3, 79-86 (2016)

6. A. Alkhatib, C. Tsang, A. Tiss, T. Bahorun, H. Arefanian, R. Barake, J. Tuomilehto, Nutrients. 9, 1310 (2017)

7. P. Patil, S. Mandal, S. K. Tomar, S. Anand, Eur. J. Nutr. 54, 863-880 (2015)

8. V. Tripathi, A. B. Abidi, S. Markerb, S. Bilal, Int. J. Pharm. Biol. Sci. 3, 434-442 (2013)

9. M. Zuk, D. Richter, J. Matuła, J. Szopa, J. Linseed, the multipurpose plant. Ind. Crops Prod. 75, 165-177 (2015)

10. M. Stacewicz-Sapuntzakis, Crit. Rev. Food Sci. Nutr. 53, 1277-1302 (2013)

11. R. Tare, Anglis. J. Assoc.-Inst. Eng. Lang. Am. Stud., 2, 133-136 (2015)

12. P. K. Vayalil, Crit. Rev. Food. Sci. Nutr. 52, 249-271 (2012)

13. J. M. Alkaabi, B. Al-Dabbagh, Sh. Ahmad, H. F. Saadi, S. Gariballa, M. A. Ghazali, Nutr. J. 10, 59 (2011)

14. W. Wolf, W. E. L. Spiess, G. Jung, Properties of water in foods, (Springer, Dordrecht, 1985)
15. L. Bell, T. Labuza, Moisture sorption: Practical aspects of isotherm measurement and use (American Association of Cereal Chemists, Inc., St. Paul, MN, 2000)

16. N. Menkov, K. Dinkov, A. Durakova, N. Toshkov, Bulg. J. Agric. Sci. 15, 281-285 (2009)

17. S. Arslan-Tontul, J. Heat Mass Transf. 57, 543-550 (2021)

18. S. Brunauer, L. S. Deming, W. E. Diming, E. Troller, JACS. 62, 1723-1732 (1940) 